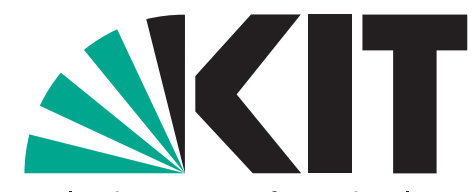

Karlsruher Institut für Technologie

\title{
Mental accounting, access motives, and overinsurance
}

by Markus Fels

No. 69 | MAY 2015

\section{WORKING PAPER SERIES IN ECONOMICS}

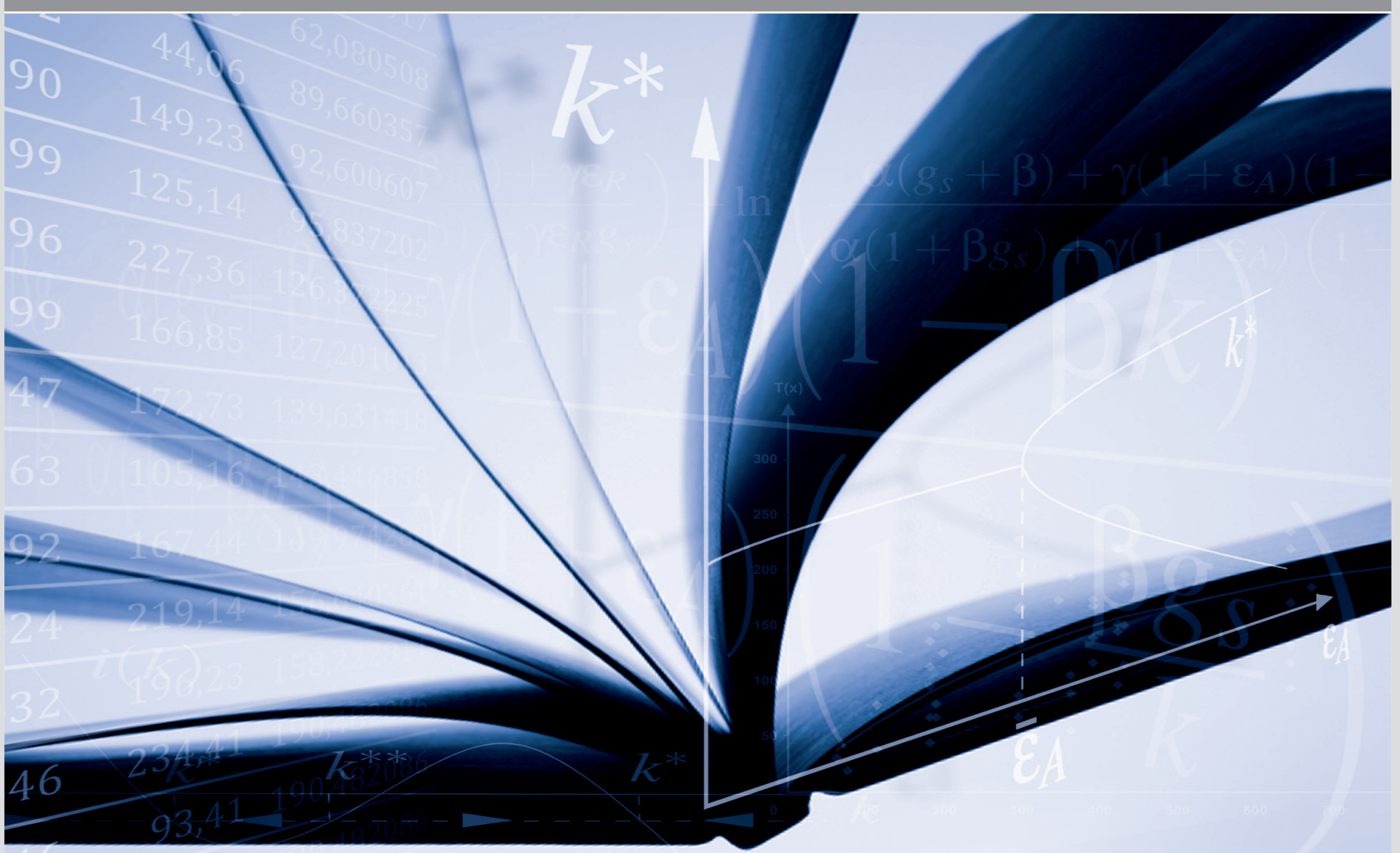




\section{Impressum}

Karlsruher Institut für Technologie (KIT)

Fakultät für Wirtschaftswissenschaften

Institut für Volkswirtschaftslehre (ECON)

Schlossbezirk 12

76131 Karlsruhe

KIT - Universität des Landes Baden-Württemberg und nationales Forschungszentrum in der Helmholtz-Gemeinschaft

Working Paper Series in Economics

No. 69, May 2015

ISSN 2190-9806

econpapers.wiwi.kit.edu 


\title{
Mental Accounting, Access Motives, and Overinsurance
}

\author{
Markus Fels* \\ $29^{\text {th }}$ May, 2015
}

\begin{abstract}
People exercising mental accounting have an additional motive for buying insurance. They perceive a risk of having insufficient funds available to self-insure. In this way insurance protects the consumption value of the insured asset beyond the expenditure to acquire/replace it. This complements previous approaches based on probability weighting and loss aversion to explain the high profitability of warranties and an aversion toward deductibles. It helps to account for why the value of a warranty is found to be positively related to the value of the product and why there is seemingly contradictory empirical evidence on how household income affects demand for warranties. The adapted model rationalizes a strong aversion to deductibles, and explains the observed sensitivity of this aversion to the insurance context. Finally, it predicts a strong impact of how an insurer pays out benefits on the value and cost of insurance. This can explain both the evidence on strong deductible aversion for flood insurance and the lack of such evidence for long-term care insurance.
\end{abstract}

\section{JEL Classification: D11, D14, D81, G22}

Keywords: Extended Warranty, Deductibles, Insurance Demand, Mental Accounting, Access Motive

${ }^{*}$ Karlsruhe Institute of Technology, Institute of Economics, Schlossbezirk 14, 76131 Karlsruhe, Germany; E-mail address: markus.fels@kit.edu. I thank the seminar audience at Karlsruhe Institute of Technology, in particular Clemens Puppe and Philipp Reiss, for valuable comments. 


\section{Introduction}

Insurance decisions have become an increasingly popular topic in behavioral economics since, on the one side, insurance markets are an integral part of modern economies, and, on the other side, these markets have produced plenty of evidence that documents departures from the benchmark of expected-utility theory. Two types of behavior that have typically been described as instances of overinsurance are the avoidance of deductibles and the purchase of extended warranties.

There is a consensus among economists that extended warranties are exploitative devices. Due to our understanding of insurance as a consumption-smoothing device, warranties cannot produce a significant surplus since people should be approximately risk-neutral with regard to the expenses that warranties insure. Consequently, the observed attractiveness of warranties to consumers and the resulting possibility for firms to reap significant profits from their sale has left economists puzzled. ${ }^{1}$ Given the discrepancy between the predictions of standard models and observed behavior, several attempts have been made to explain this sort of behavior as an instance of mistaken decision-making. First, the overestimation of the claim probability has been proposed as a possible explanation, either because of probability weighting or because of an underestimation of future claim cost. $^{2}$ In addition, myopic loss-aversion has been identified as a possible reason for warranty purchase. $^{3}$ There is empirical evidence supporting both the view that customers overestimate the claim probability and the view that consumers' loss aversion plays an important role in the purchase of warranties. ${ }^{4}$ Yet, there is also empirical evidence calling into question whether this can be the whole story. First, it has been observed that customers' willingness-topay for warranties is strongly related to the value of the product (Chen, Kalra, and Sun (2009) and OFT (2012)). Second, despite the high profitability of warranties, their sale is often confined to expensive products (OFT (2012)). Finally, there is evidence suggesting that warranty purchase may vary with income - yet the sign of the variation differs across studies. ${ }^{5}$ Neither the standard model of insurance nor the behavioral models of mistaken overinsurance are able to explain these

\footnotetext{
${ }^{1}$ In a much noted article, Businessweek (2004) reports that "profits from warranties accounted for all of Circuit City's operating income and almost half of Best Buy's". Ten years later, Warranty Week (2014) notes in its 2014 Mid-Year Service Contract Report that "Consumers will pay nearly $\$ 40$ billion this year for product protection plans, despite the best efforts of watchdogs who tell them not to".

${ }^{2}$ See e.g. Cutler and Zeckhauser (2004), and Michel (2014)

${ }^{3}$ See e.g. Rabin and Thaler (2001).

${ }^{4}$ See e.g. Jindahl (2014).

${ }^{5}$ Chen, Kalra, and Sun (2009) find a negative relationship for warranties covering electronic devices. Padmanabhan and Rao (1993) find a positive relationship for extended service contracts for cars. Chu and Chintagunta (2011) find a concave relationship between income and the duration of a purchased car warranty.
} 
empirical patterns.

At the same time, deductibles are an important part of insurance contracts in most insurance markets. This is based on the insight from insurance economics that a certain amount of risk sharing through deductibles helps to mitigate moral hazard. As long as consumers retain a "modest" amount of risk, the utility loss from incomplete coverage is negligible since consumers should be approximately risk neutral with regard to the stakes created by deductibles. In contrast to this prediction, consumers seem willing to bear significant premium increases in order to decrease or even fully eliminate the deductible prescribed by an insurance policy. Again, the most popular explanations for this discrepancy are probability weighting and/or loss aversion. ${ }^{6}$ While these approaches succeed in predicting an aversion towards deductibles, they fail to explain the observed context sensitivity of this aversion. ${ }^{7}$ Deductible avoidance has been documented in the context of flood insurance (Michel-Kerjan and Kousky (2010)), a market typically associated with probability underweighting, not overweighting. At the same time, Brown and Finkelstein (2007) find no evidence for deductible avoidance in the US market for private long-term care (LTC) insurance. The latter is particularly surprising as deductibles in the LTC insurance market are sizable enough that even standard expected-utility theory predicts more comprehensive insurance to be desirable.

I argue that a part of our models' inability to explain the observed attractiveness of warranties and unattractiveness of deductibles is a result of these models confining the value of insurance to its consumption-smoothing role. That is, part of economists' puzzle with regard to warranty demand and deductible avoidance is due to risk aversion being regarded as the single motive for buying insurance.

Following an idea initially proposed by Nyman (2003) in the context of health insurance, I argue that insurance can be valuable as it helps to overcome budget constraints. having experienced the loss of an asset (sickness, product failure), an individual may not possess the funds that are necessary to remedy the loss (medical expenditure, product replacement or repair). An insurance eliminates or at least alleviates this budget risk thereby granting the individual access to the remedy that financial contraints would otherwise inhibit. In this way, an insurance protects the consumption value of the insured asset. This is not the case in the standard view of insurance, in which insurance is a device to mitigate the consumption variation due to the cost of the remedy.

\footnotetext{
${ }^{6}$ See e.g. Johnson, Hershey, Meszaros, and Kunreuther (2000), Sydnor (2010), and Barseghyan, Molinari, O'Donoghue, and Teitelbaum (2013).

${ }^{7}$ See Barseghyan, Prince, and Teitelbaum (2011).
} 
I argue that this access motive is also relevant for modest stakes such as the expenses insured by warranties or the expenses to pay a deductible since there is ample evidence that people have a tendency to perform mental accounting. ${ }^{8}$ With this minor modification, the model can explain why there is a significant gap between a customer's willingness-to-pay for the warranty and its actuarial value even if the customer does not misjudge the claim probability. This allows a seller to reap significant monopoly profits from selling warranties. Second, it explains why a customer's valuation for a warranty is related to his valuation of the insured product. Finally, it explains why poorer customers as well as customers that buy the product on promotion are more likely to buy a warranty (Chen, Kalra, and Sun (2009)) and why warranties are more likely to be sold on expensive products (OFT (2012)). Allowing for a deductible, I show that the sign of this income effect changes with the size of the deductible. This is because a poorer customer may envisage the possibility of not being able to pay the deductible, making the insurance policy effectively worthless. As this risk increases in the size of the deductible, customers can show a strong aversion towards deductibles. Also, it can explain why a negative income effect has been observed for warranties insuring electronics that come with no deductible (Chen, Kalra, and Sun (2009)), while a positive income effect or a concave effect has been observed for extended service contracts for cars that typically involve a deductible (Padmanabhan and Rao (1993); Chu and Chintagunta (2011)). Investigating the attitudes towards deductibles that the model predicts, I find that deductible avoidance is strongly related to the value of the insured asset. That can explain the evidence on context-dependence of deductible avoidance that has been documented by Barseghyan, Prince, and Teitelbaum (2011). Finally, I show that the way an insurance pays benefits has a strong effect on both the value and the cost of insurance. In particular, there is a strict order in both value and cost of insurance dependent on whether insurance benefits are paid unconditionally, conditional on a deductible payment, or by reimbursement. This is because insurance benefits are paid in all loss states in the first case. In the second case, they are paid only in the states in which the insuree is able to pay the deductible. In the case of reimbursement, they are only paid in the states in which the insuree is able to advance the money to cover the complete loss. The different valuations dependent on payment style can rationalize why a strong deductible avoidance is observed for flood insurance (Michel-Kerjan and Kousky (2010)), where benefits are paid unconditionally. At the same time, it can explain why there is no evidence for deductible avoidance in the private market for LTC insurance in the US, in which benefits have

\footnotetext{
${ }^{8}$ See e.g. Thaler (1990), Heath and Soll (1996), Thaler (1999), and Hastings and Shapiro (2012).
} 
traditionally been paid by reimbursement (Brown and Finkelstein (2007)).

I proceed as follows. In section 1, I use a simple model to show why a standard model cannot account for the substantial profit margins in warranty markets and the strength of deductible avoidance that is typically observed. I show how assuming loss aversion or probability weighting can help to overcome this discrepancy. I continue by pointing out that these alternative approaches are still unable to accomodate several empirical patterns concerning warranty demand and deductible avoidance. In section 2, I introduce a simple modification that is applicable both to the standard model and behavioral models of insurance and can account for the large profit margins in the warranty markets as well as additional empirical patterns. Section 3 explains why deductible avoidance is context-dependent and discusses the role of deductibles in accounting for seemingly contradictory evidence on the impact of household income on warranty purchase. In section 4, I show how the payment details of an insurance contract significantly affect its value and cost, as well as customers' attitudes toward deductibles. Section 5 discusses the role of mental accounting for producing the additional insurance motive that is proposed. Also, I outline how this adaptation complements previous approaches based on probability weighting and/or loss aversion. Finally, I discuss the relationship with the literature on background risk and risk taking. In section 6, I conclude. All proofs are deferred to the Appendix.

\section{A Simple Model of Insurance}

Suppose an individual possesses an asset that he values at $V$. That asset can take several forms: a consumption good - a plasma TV, a cell phone, or a car - or his good health, i.e. the absence of a disease. There is a probability $\pi \in(0,1)$ that he looses this asset: the TV or car may malfunction, or he may be striken by a disease. In all of these cases, there is a remedy available at a price $p<V$ : repair or replacement of the consumption good, or a treatment for the disease that returns the individual to good health. The individual will then purchase the remedy in case of a loss. His utility without insurance is thus given by

$$
\mathbb{E} u_{0}=(1-\pi) u(V)+\pi u(V-p) .
$$


Suppose now, the individual is offered an insurance at a price $w$ that completely covers the cost of the remedy $p$ in case of a loss. His utility with insurance is then given by

$$
\mathbb{E} u_{I}=u(V-w)
$$

Thus, the individual will purchase the insurance if and only if

$$
\mathbb{E} u_{I}-\mathbb{E} u_{0} \geq 0 \Leftrightarrow w \leq \pi p+\text { risk premium. }
$$

With a similar logic, the maximal willingness-to-pay to avoid a deductible $r \in(0, p)$ can be calculated by replacing $p$ with $r$ in equation (1) and subtracting it from the utility of full insurance given by (2). This gives a maximal willingness-to-pay of $(\pi r+$ risk premium) to avoid a deductible of size $r$.

There are many instances in which it is argued that the risk premium is - or should be negligible in these calculations. When the stakes are modest, people should be approximately risk neutral. ${ }^{9}$ That is, if $p$ is modest, as is argued in the case of e.g. extended warranties, then the maximal willingness-to-pay for this warranty should be approximately $\pi p$. In other settings, such as home, car, or health insurance, it is argued that at least the deductibles are low enough that people should be approximately risk-neutral with regard to the stakes imposed by deductibles. Hence, these people should show a maximal willingness-to-pay of approximately $\pi r$ to avoid a deductible. These considerations allow for a couple of straightforward predictions.

1. There are no (significant) gains from trade generated by extended warranties. Hence, a monopolist is not be able to reap significant profits from their sale. Furthermore, competitive pressure in the market for warranties has no significant effect on warranty prices.

2. Controlling for the price of the product $p$, there is a negative correlation between the willingness-to-pay for the product and the willingness-to-pay for the warranty. This is the result of the first being negatively related to break-down risk, and the second being positively related to break-down risk. Controlling for both price and break-down probability, there is no correlation between the two.

3. There is no correlation between the willingness-to-pay for warranties and the income of the

\footnotetext{
${ }^{9}$ See e.g. Rabin (2000), and Rabin and Thaler (2001).
} 
customer.

4. Insurees are willing to accept a (higher) deductible $r$ as long as they are compensated with a reduction in the premium $w$ that is (slightly more favorable than) actuarially fair: $\pi r$.

5. The willingness-to-pay to avoid a deductible is a function of $\pi$ and $r$ alone.

Let us contrast these with the empirical findings concerning warranties and deductible avoidance:

1. Firms make significant profits from the sale of extended warranties. Competition in warranty markets drives down prices (Businessweek (2004), OFT (2012)).

2. There seems to be a positive correlation between the value of the product and the willingnessto-pay for a warranty (Chen, Kalra, and Sun (2009), OFT (2012), Chark and Muthukrishnan $(2013))$.

3. There is a significant correlation between warranty purchase and income. The sign of this correlation varies across studies (Padmanabhan and Rao (1993), Chen, Kalra, and Sun (2009), Chu and Chintagunta (2011)).

4. Insurees require a reduction of the premium that is much larger than $\pi r$ in order to choose a (higher) deductible (Sydnor (2010)).

5. The existence and extent of deductible avoidance is context-dependent (Barseghyan, Prince, and Teitelbaum (2011), Michel-Kerjan and Kousky (2010), Brown and Finkelstein (2007)).

These empirical findings are hence at odds with the standard model's theoretical prediction. The most prominent approaches to address these discrepancies typically focus on the first and fourth point. They posit that customers overweight the break-down probability $\pi$, either because they perform probability weighting, or because they overestimate the probability with which they make a claim. Alternatively, people's loss aversion can lead them to overweight the payments $p$ (or $r$ respectively). These approaches are successful in predicting a positive wedge between the willingness-to-pay $\bar{w}$ for the warranty and the expected cost of coverage:

$$
\begin{gathered}
\bar{w}-\pi p=\omega(\pi) p-\pi p=(\omega(\pi)-\pi) p>0, \\
\bar{w}-\pi p=\pi \lambda p-\pi p=(\lambda-1) \pi p>0 .
\end{gathered}
$$


with $\omega(\cdot)$ denoting a probability-weighting function, and $\lambda$ denoting a parameter measuring the degree of loss aversion. It easy to see that such modifications can result in a firm with market power to be able to sell a warranty with positive profit. The same modifications can explain why consumers are found to demand a premium reduction of larger than $\pi r$ in order to accept a deductible. These behavioral approaches can thus explain the profitability of warranties and the avoidance of deductibles. However, given that these approaches only change the weighting of either $\pi$ and/or $p(r)$, they cannot account for the influence of other variables, such as product value or income.

In the following, I want to suggest a simple way to accomodate all of these observations. It suggests that one reason for the discrepancy between the predictions of standard insurance models and observed behavior may lie in these models narrowing insurance motives down to consumptionsmoothing motives. In this way, we fail to take into account a significant value that insurance creates.

\section{Budget Constraints}

Contrary to the initial model, suppose now that for some reason, the consumer expects a chance to be unable to pay $p$ in case of a loss. We discuss this central assumption and its relation to the concept of mental accounting in more detail in section 5. Suppose for simplicity, the probability that the consumer is unable to repurchase the product is given by $0<\rho<1$ and independent of break-down. In this case, the utility from self-insuring to a risk-neutral individual ${ }^{10}$ is given by

$$
\mathbb{E} u_{0}=(1-\pi) V+\pi(1-\rho)(V-p)
$$

As the outside option becomes less attractive, this changes the consumer's valuation of insurance as measured by his maximal willingness-to-pay.

Proposition 1. A risk-neutral individual has a maximum willingness-to-pay of $\bar{w}=\pi(\rho V+(1-$ $\rho) p)=\pi p+\pi \rho(V-p)$ for full insurance.

If the individual perceives a chance to be unable to pay $p$ in case of a loss, then insurance

\footnotetext{
${ }^{10} \mathrm{I}$ assume risk neutrality throughout the whole derivation in order to carve out the effects that are entirely due to the modification that is proposed here.
} 
creates an additional value. It ensures the individual to have access to the loss remedy even if his own funds do not suffice to purchase it on his own. Accordingly, this value has been termed access value in the context of health insurance (Nyman (2003)). I argue here that this value is of interest more generally. In particular, when people perform mental accounting they can perceive a risk of not being able to pay $p$ even if $p$ is rather modest. In addition, as we argue in the next section, they can perceive a chance of being unable to pay even a deductible. Note the following comparative statics that result from this proposition. First, $\bar{w}$ strictly increases in $V$ as long as $\rho>0$. This can explain a positive correlation between the willingness-to-pay for a warranty and the willingness-to-pay for the product, even after controlling for both price and break-down risk. Second, $\bar{w}$ strictly increases in $\rho$ as long as $p<V$. Hence, people with a higher budget risk are predicted to have a larger willingness-to-pay for warranties that fully replace a broken product. This is consistent with poorer people showing a stronger inclination to purchase such warranties. Since the budget risk $\rho$ simply measures the probability with which a customer expects not to be able to repurchase the product in case of break-down, this comparative static is also consistent with the finding that a warranty purchase is more likely if the product was bought at a promotion price (Chen, Kalra, and Sun (2009)). Third, if $F(x)$ is the distribution associated with the customer's available budget, with $f(x)$ being the associated density, then $\frac{\partial \bar{w}}{\partial p} \geq \pi$ if and only if $f(p)(V-p) \geq F(p)$. We can expect this latter inequality to be fulfilled in markets in which (a) there is competition in the base good market, such that $p$ is low, and (b) a high-value product is sold, such that $V$ is high. If this inequality is fulfilled, then the willingness-to-pay is predicted to respond stronger to changes in $p$ than predicted by the standard model. Such an overresponse has typically been interpreted as evidence of probability weighting and/or loss aversion.

Finally, note the following relationship between the monopoly profit from selling a warranty and the level of competition in the base good market. The profit is given by $\pi \rho(V-p)$. Since $\rho=F(p)$, there is a nonmonotonic relationship between the profit from selling warranties and the price of the base good $p$. At $p=V$, the profit from the sale of the warranty is strictly decreasing in $p$. If $p$ is low (and $V$ is high), the profit from selling warranties is increasing in p. In contrast, behavioral models predict a strictly positive relationship between the profits in the warranty market and the price in the base market. ${ }^{11}$ Alternative models thus predict fierce competition in the base good market also to reduce profits in the warranty markets. Yet, in the market for consumer electronics we have seen fierce competition, shrinking profit margins for the

\footnotetext{
${ }^{11}$ This is easy to see, since the profit in these models is given by $(\omega(\pi)-\pi) p$ or $\pi(\lambda-1) p$.
} 
base goods close to zero, while profits on extended warranties remain substantial. The adaptation that is proposed here can capture such a different development in profits from the sale of base goods and from the sale of warranties.

In the following, I seek to derive the value of insurance if this insurance comes with a deductible of size $r$. This allows to investigate the attitudes towards deductibles that the adaptation predicts. Also, I want to point out how the existence of a deductible can explain the seemingly contradictory evidence on the effect of income on warranty purchase.

\section{Partial Insurance}

Consider the case in which the insuree has to pay a deductible $r<p$ when making a claim. A risk-neutral individual derives a utility

$$
\mathbb{E} u_{I(r)}=(1-\pi)(V-w)+\pi[(1-\rho)(V-w-r)+\rho(-w)]
$$

from such an insurance. Hence, he has a maximal willingness-to-pay of

$$
\begin{aligned}
\bar{w}(r) & =\pi[(p-r)+\rho(V-p)-\delta(V-r)] \\
& =\pi[(p-r)+\underbrace{(\rho-\delta)(V-p)}_{\text {access value }} \underbrace{-\delta(p-r)}_{\text {claim risk }}]
\end{aligned}
$$

where $\rho=F(p), \delta=F(r)$. Equation (8) indicates two reasons for people to avoid deductibles even in the absence of probability weighting or loss aversion. First, a deductible reduces the access value provided by insurance. With a probability $\delta=F(r)$, the individual's budget falls below $r$. In this case, even if he receives a benefit payment $p-r$ by the insurer, he cannot make the payment $p$ that is necessary to avoid the loss of $V$. Second, very frequently, the benefit payment is conditional on deductible payment. ${ }^{12}$ If that is the case, the insuree perceives a claim risk of $\delta=F(r)$ that he will not receive any insurance benefit despite incurring a loss. Due to these two effects, the model predicts a willingness of $\pi r+\pi \delta(V-r)>\pi r$ to avoid a deductible.

\footnotetext{
${ }^{12}$ This is the case for health insurance or for car warranties among others. If the insuree is unable to pay his part $r$ of the bill, he receives no service. And if he does not receive any service, the insurer need not settle any claims. A deductible can thus prevent an insuree from filing a claim in case of a loss. This claim risk depends on the way in which the insurance pays benefits. We will return to this point in the following section.
} 
More generally, for any two deductibles $r_{h}, r_{l}$ with $0 \leq r_{l}<r_{h}<p$, it is argued that for the typical sizes of deductibles observed, consumers should behave approximately risk-neutral. That is, the difference $\bar{w}\left(r_{l}\right)-\bar{w}\left(r_{h}\right)$ is predicted to be approximately $\pi\left(r_{h}-r_{l}\right)$. Yet, the observed willingness-to-pay for a lower deductible often far exceeds that value. Our model can predict a strong aversion to higher deductibles and can thus complement previous approaches based on probability weighting and loss aversion.

Proposition 2. For any two deductibles $r_{h}, r_{l}$ with $0 \leq r_{l}<r_{h}<p$, the willingness-to-pay for the lower deductible exceeds the value $\pi\left(r_{h}-r_{l}\right)$ if and only if

$$
\frac{F\left(r_{h}\right)-F\left(r_{l}\right)}{F\left(r_{h}\right)}>\frac{r_{h}-r_{l}}{V-r_{l}}
$$

The model predicts an aversion to deductibles if the relative increase in budget risk due to the higher deductible exceeds the reduction in consumer surplus due to the higher deductible. Note that this predicts a stronger aversion towards deductibles for insurances covering assets of higher value $V$. This is consistent with evidence presented by Barseghyan, Prince, and Teitelbaum (2011) who find a stronger inclination to choose a lower deductible for home as compared to car insurance.

In addition, the presence of a deductible can explain the seemingly contradictory evidence on the effect of income on warranty purchase. While Chen, Kalra, and Sun (2009) find a negative effect, Padmanabhan and Rao (1993) find it to be positive effect. Chu and Chintagunta (2011) find a concace relationship between income and warranty purchase. Yet, there is a notable difference between these studies. Chen, Kalra, and Sun (2009) consider warranties for consumer electronics that typically offer full insurance through repair or replacement of a broken device. In contrast, the other two studies consider car warranties that typically prescribe a deductible. In section 2 , it was already shown that the model predicts a negative effect of income on the willingness-to-pay for full insurance. Thus, the model can explain the negative effect found in Chen, Kalra, and Sun (2009). I want to show how the sign of this effect can switch from negative to positive if the insurance prescribes a deductible payment.

Let $F_{i}, i=H, L$ denote the budget risk of the poor $(H)$ and the rich $(L)$ group. ${ }^{13}$ Then the willingness of the rich group $\bar{w}_{H}$ is higher than the willingness-to-pay of the poor group $\bar{w}_{L}$ if and

\footnotetext{
${ }^{13} \mathrm{I}$ assume $F_{i}(0)=0, i=H, L$ throughout.
} 
only if

$$
\left[F_{H}(p)-F_{L}(p)\right](V-p)<\left[F_{H}(r)-F_{L}(r)\right](V-r)
$$

Since $r \leq p$, a sufficient condition is $F_{H}(p)-F_{H}(r)<F_{L}(p)-F_{L}(r)$. The difference $F(p)-F(r)$ is the joint probability with which the individual expects to be unable to bear the full remedy cost $p$, yet able to pay the deductible $r$. If this joint probability is lower for poorer customers than for richer customers, the richer group has a higher willingness-to-pay for the warranty.

Proposition 3. Let $F_{\theta}, \theta=L, H$ be twice continuously-differentiable and let $F_{L}$ first-order stochastically dominate $F_{H}$. Suppose further, $F_{H}(x)-F_{L}(x)>0$ for some $0<x<V$, and denote by $x^{*}<V$ a maximum of $\phi(x)=\left(F_{H}(x)-F_{L}(x)\right)(V-x)$.

Then there exist $p, r: 0<r<p<V$ such that $\bar{w}_{L}(r)>\bar{w}_{H}(r)$.

Suppose, in addition, that $x^{*}$ is the unique interior maximum of $\phi(x)$ and $\phi^{\prime}>0, \forall x<x^{*}$ and $\phi^{\prime}<0, \forall x>x^{*}$. Then, if $p \leq x^{*}, \bar{w}_{H}(r)>\bar{w}_{L}(r) \forall r<p$. Yet, if $p>x^{*}$, then $\exists$ ! $r^{*}<p$ : $\bar{w}_{H}(r)>\bar{w}_{L}(r), \forall r<r^{*}$ and $\bar{w}_{H}(r) \leq \bar{w}_{L}(r), \forall r \geq r^{*}$, with strict inequality for all $r \in\left(r^{*}, p\right)$.

Furthermore, $\lim _{\left(F_{H}(p)-F_{L}(p)\right) \rightarrow 0} r^{*}=0$.

Intuitively, a deductible reduces the access value and produces a claim risk, as argued previously. While it is not clear a priori which group enjoys a larger access value when the insurance prescribes a deductible, it is clear that the poorer group perceives a larger claim risk than the richer group. Once the difference in claim risk dominates the difference in access value, the richer customer group ascribes a larger value to the insurance. Moreover, if $p$ is large enough such that the difference in access value becomes negligible, as $F_{L}(p) \approx F_{H}(p)$, then this domination occurs for very small deductibles already. This can explain the differing results on the relationship between income and willingness-to-pay for warranties. It explains a negative effect of income on warranty purchase when investigating markets for consumer electronics where typically there are no deductibles. At the same time, it explains evidence on a positive relationship for extended warranties in cars that often prescribe a deductible. ${ }^{14}$

Finally, allowing for nonlinear relationships Chu and Chintagunta (2011) find evidence on a concave relationship between income and propensity for warranty purchase. The model is able to

\footnotetext{
${ }^{14}$ Some car warranties do not work with conditional benefit payment, but through reimbursing the insuree once he hands in proof of payment for $p$. In the following section, I discuss the impact of this different way of paying benefits. I seek to highlight here that under reimbursement, the model predicts the effect of income to always be positive.
} 
explain such a finding as well.

Suppose there are three groups with different budget risk: high (H), medium (M), and low (L). Let $F_{i}, i=H, M, L$ denote the budget risk of type $i$ where $F_{L}\left(F_{M}\right)$ first-order stochastically dominates $F_{M}\left(F_{H}\right)$. Denote by $\phi_{H M}=\left(F_{H}(x)-F_{M}(x)\right)(V-x), \phi_{H L}=\left(F_{H}(x)-F_{L}(x)\right)(V-x)$, and $\phi_{M L}=\left(F_{M}(x)-F_{L}(x)\right)(V-x)$. Suppose further that for all these three functions, there exists a unique maximum $x_{j}^{*}, j=H M, H L, M L$ and $\phi_{j}^{\prime}(x)>0$ for all $x<x_{j}^{*}$ and $\phi_{j}^{\prime}(x)<0$ for all $x>x_{j}^{*}$. Let $r_{H M}^{*}$ denote the minimum deductible $r$ such that $\bar{w}_{H}(r) \geq \bar{w}_{M}(r), \forall r \leq r_{H M}^{*}$ and $\bar{w}(r)_{H}<\bar{w}_{M}(r), \forall r_{H M}^{*}<r<p .{ }^{15}$ Define $r_{j}^{*}, j=H L, M L$ accordingly. This allows to state the following result.

Proposition 4. Suppose that for any $x^{\prime}>x$, if $\phi_{H L}(x)=\phi_{H L}\left(x^{\prime}\right)$, then $\phi_{M L}(x) \leq \phi_{M L}\left(x^{\prime}\right)$.

Then, it holds that $r_{H M}^{*} \leq r_{H L}^{*} \leq r_{M L}^{*}$.

The condition specified in Proposition 4 rules out that the largest differences between the distributions $F_{M}$ and $F_{L}$ occur at lower $x$ than the largest differences between $F_{H}$ and $F_{L}$. If the above ordering of $r_{j}^{*}$ is possible, then the effect of income on the willingness-to-pay for a warranty is a simple function of the deductible $r$.

Corollary 1. If the condition specified in Proposition 4 is met, then for any $r<r_{H M}^{*}$ the willingness-to-pay for a warranty is strictly decreasing in income: $\bar{w}_{L}<$ $\bar{w}_{M}<\bar{w}_{H}$,

for any $r_{H M}^{*}<r<r_{M L}^{*}$, the willingness-to-pay for a warranty is concave in income: $\bar{w}_{L}<\bar{w}_{M}$ and $\bar{w}_{H}<\bar{w}_{M}$,

and for any $r_{M L}^{*}<r<p$, the willingness-to-pay for a warranty is strictly increasing in income: $\bar{w}_{L}>\bar{w}_{M}>\bar{w}_{H}$.

Propositions 3 and 4, as well as Corollary 1 show that the size of the deductible may influence the effect of income on people's incliniation to buy a warranty. This influence helps explain why Chen, Kalra, and Sun (2009) find a negative effect of income in electronics markets, while Chu and Chintagunta (2011) find a concave relationship and Padmanabhan and Rao (1993) find a positive relationship for car warranties. ${ }^{16}$

\footnotetext{
${ }^{15}$ Note that if $p<x_{j}^{*}$, then $r_{j}^{*}=p$.

${ }^{16} \mathrm{Chu}$ and Chintagunta (2011) find a negative relationship between firm size and warranty demand in the market for computer servers. If one reinterprets the budget risk $F(x)$ as the probability with which a firm holds insufficient liquid ressources to replace a broken server and assumes this risk to be larger for smaller firms, the model can accomodate this finding without assuming different degrees of risk aversion between smaller and larger firms.
} 


\section{Payment details matter}

In the last section, the production of a claim risk was given as one reason why consumers dislike deductibles. This consequence of deductibles, as well as their impact on the access value, are a function of how the insurance pays out benefits. The economic analysis of insurance has not been given particular attention to this feature of insurance contracts to date. Yet, it is quite important if consumers perceive a budget risk since their valuation of insurance then depends on that perception.

Consider the following three cases.

In the first case, the case we have considered so far, the customer has to pay the deductible $r$ when making a claim. That is, the insurer only pays the benefit $(p-r)$ if the claimant is able (and willing) to pay the deductible. The benefit payment is then conditional on the deductible payment. If that is the case, a customer perceiving a budget risk anticipates the possibility that he will be unable to pay the deductible, in which case the insurance is worthless. However, if the insuree is able to pay the deductible $r$, he is able to claim the benefit $p-r$ that ensures him to be able to pay $p$ and thereby protect the asset value $V$. This is particularly helpful in those cases in which he could not afford to pay $p$ on his own. In this way, the insurance provides an access value. Summing up, if benefits are paid conditionally, the insurance provides an access value with probability $F(p)-F(r)$, yet imposes a claim risk of not paying any benefits with probability $F(r)$.

In contrast, consider the case in which the insurance pays out a benefit of $(p-r)$ in case of a loss no matter whether the customer pays the deductible. That is, the insurer pays the benefits unconditionally. Flood insurance is a prominent example of this practice. In contrast to conditional payment, the insurer pays the benefit $(p-r)$ no matter whether the insuree is able to pay the deductible. Hence, a deductible does not impose a claim risk under unconditional payment. Equal to the case of conditional payment, the insurance payment $(p-r)$ allows the insuree to pay $p$ and thereby protect the asset value $V$ if and only if he is able to pay the deductible $r$ which is of particular value when he could not have done this without the insurance payment. Summing up, if benefits are paid unconditionally, the insurance provides an access value with probability $F(p)-F(r)$, yet in contrast to conditional payment it imposes no claim risk.

Finally, consider the practice of reimbursement. In this case, the insuree has to advance the full price $p$ in case of a loss and is then reimbursed a fraction $p-r$ by the insurer. This practice 
produces the largest claim risk, for an insuree is able to make a claim if and only if he is able to pay $p .{ }^{17}$ At the same time, the insuree is able to pay $p$ and thus protect the asset $V$ if and only if his own budget suffices to pay $p$. Yet, this is already the case under self-insurance. An insurance that pays benefits through reimbursement hence produces no access value. In sum, if benefits are paid by reimbursement, the insurance provides no access value, yet imposes a claim risk of not paying any benefits with probability $F(p)$.

These considerations explain why and how the details of benefit payment affect the value of insurance to customers. At the same time, insurers expected cost of coverage are influenced by the claim risk since benefits have to be paid only if a claim is made. Denote by $\bar{w}_{c}, \bar{w}_{u c}, \bar{w}_{r i}$ the maximal willingness-to-pay for the insurance and by $f_{c}, f_{u c}, f_{r i}$ the actuarially fair price of the insurance. Then it is possible to make the following statement.

Proposition 5. (i) The maximal willingness-to-pay for the three types of insurance is given by

$$
\begin{aligned}
& \bar{w}_{c}=\pi[(p-r)+\rho(V-p)-\delta(V-r)], \\
& \bar{w}_{u c}=\pi[(p-r)+(\rho-\delta)(V-p)], \\
& \bar{w}_{r i}=\pi[(1-\rho)(p-r)],
\end{aligned}
$$

and, hence,

(ii) $\bar{w}_{u c} \geq \bar{w}_{c} \geq \bar{w}_{r i}$, with strict inequality for all $0<r<p$.

(iii) The actuarially fair price of the three types of insurance is given by

$$
\begin{aligned}
& f_{c}=\pi(1-\delta)(p-r) \\
& f_{u c}=\pi(p-r) \\
& f_{r i}=\pi(1-\rho)(p-r),
\end{aligned}
$$

and, hence,

(iv) $f_{u c} \geq f_{c} \geq f_{r i}$, with strict inequality for all $0<r<p$.

Proposition 5,(i) and (ii) show that customers perceiving a budget risk ascribe different values to an insurance depending on its method to pay benefits. Parts (iii) and (iv) of Proposition 5 indicate that, when customers perceive a budget risk, the cost of insurance provision depend on

\footnotetext{
${ }^{17}$ Note, however, that, in contrast to conditional payment, this claim risk is independent of the deductible $r$.
} 
the method of benefit payment as well. Since the different methods of payment exclude some insurees from claiming benefits despite having incurred a loss, the methods of payment can be ranked according to the expected cost of coverage as well.

These results allow interesting welfare comparisons. Let $s_{b}=\bar{w}_{b}-f_{b}$ be the gains from trade created by an insurance of type $b=c, u c, r i$.

Corollary 2. The gains from trade created by insurance are given by

$$
s_{c}=s_{u c}=\pi(\rho-\delta)(V-p) \geq 0=s_{r i},
$$

with strict inequality for all $r<p$.

Corollary 2 shows that unconditional and conditional benefit payment are equivalent from a welfare perspective, while being superior to reimbursement. Note that this is due to our model confining the value of insurance to its access value: the value it provides by enabling the insuree to pay $p$ when he is unable to do so on his own. The probability of having insufficient resources to do so when insured equals $\delta=F(r)$ under conditional and unconditional payment. It equals $F(p)=\rho$ under reimbursement, the same probability the customer would face when self-insuring. Thus reimbursement does not provide any access value and thus creates no gains from trade. ${ }^{18}$

Beside the welfare implications, the different payment methods predict different attitudes toward deductibles.

Corollary 3. For any two deductibles $r_{h}, r_{l}$ with $0 \leq r_{l}<r_{h}<p$, the willingness-to-pay for the lower deductible

(i) is given by $\left.\bar{w}_{u c}\left(r_{l}\right)-\bar{w}_{u c}\left(r_{h}\right)=\pi\left[\left(r_{h}-r_{l}\right)+\left(F\left(r_{h}\right)-F_{(} r_{l}\right)\right)(V-p)\right]>\pi\left(r_{h}-r_{l}\right)$ if benefits are paid unconditionally, and

(ii) is given by $\bar{w}_{r i}\left(r_{l}\right)-\bar{w}_{r i}\left(r_{h}\right)=\pi(1-\rho)\left(r_{h}-r_{l}\right)<\pi\left(r_{h}-r_{l}\right)$ if benefits are paid as reimbursement.

\footnotetext{
${ }^{18} \mathrm{An}$ interesting addition to this analysis would be to consider the classic consumption-smooting motive in addition to the access motive that is modeled here. An unconditional benefit payment transfers money to the insuree in all loss states. In contrast, conditional benefit payments exclude insurance coverage in states in which the budget falls below $r$. Finally, reimbursement excludes insurance coverage in states in which the budget falls below $p$. Thus, a risk-averse individual would derive strictly more utility from unconditional benefits than from conditional benefits, and strictly more utility from conditional benefits than from reimbursement. We can conclude that considering both access and consumption-smoothing motive would sharpen the prediction. Unconditional benefit payments then provide strictly larger welfare than the less expensive form of conditional benefit payments. In addition, the welfare gain resulting from a switch from reimbursement to the more expensive form of conditional benefit payments would increase.
} 
Corollary 3 shows that there is always a stronger aversion towards higher deductibles as compared to the risk-neutral benchmark with no access motive when benefits are paid unconditionally. This is because the access value is strictly decreasing in $r$. Since the access value is a function of $V$, this inclination to buy lower deductibles is rising in $V$. At the same time, there is a weaker aversion towards higher deductibles when benefits are paid through reimbursement. This is because (a) the insurance provides no access value, and (b) imposes a positive claim risk that is independent of $r$. These predictions are interesting when compared to empirical evidence.

First, despite the general agreement that the uptake of flood insurance suffers from people underweighting the probability of such events, Michel-Kerjan and Kousky (2010) find only 3 percent of policyholders to have the largest possible, while almost 80 percent chose the lowest possible deductible. Flood insurance benefits are paid unconditionally. ${ }^{19}$

At the same time, the market for private long-term care insurance in the US suffers from low uptake. Note that in this market insurance benefits have traditionally been paid in the form of reimbursement. ${ }^{20}$ The model predicts such a form of insurance to provide no access value which might be one factor contributing to the low demand. In addition, it is exactly in this market in which deductibles are quite sizable as compared to other markets that Brown and Finkelstein (2007) find no evidence of customers seeking lower deductibles. On the contrary, they find customers to choose high deductibles despite more comprehensive coverage being available. Such a low attractiveness of deductibles in the long-term care insurance market is in line with our model's prediction of a low inclination to avoid deductibles when benefits are paid by reimbursement.

\section{Discussion}

\subsection{Budget Risk and Mental Accounting}

The argument that an anticipated budget risk increases the willingness-to-pay for full insurance or for a lower deductible rests on the assumption that the decision-maker expects himself to be unable to pay the price $p$ and/or the deductible $r$ in case of a loss. A mere unwillingness to pay

\footnotetext{
${ }^{19}$ It is, however, important to note that the access motive alone does not predict limited uptake. This suggests an interesting role for performing the proposed adaptation on a model involving probability underweighting. While probability underweighting alone cannot explain the inclination to buy lower deductibles, the access model alone cannot explain limited uptake. A hybrid model could explain both observations.

${ }^{20}$ This is about to change, however, as more and more providers offer benefit payments in indemnity or disability form.
} 
$p$ does not increase $\bar{w}$, since the monetary valuation $V$ of the product then falls below $p$.

It is important to ask why people can perceive a significant budget risk with respect to the expenses covered by warranties or imposed by deductibles. Here, the observed tendency for mental accounting plays a crucial role. People have been found to subdivide the entire available budget into different budget categories, considering money to be imperfectly fungible between those categories. $^{21}$ The relevant budget that is available for paying $p$ or $r$ is then substantially smaller than the whole budget of a household. Instead, these expenses will be compared to the implicit or explicit budget associated with the consumption category of the asset that is insured. This tendency for mental categorization of expenses then leads a decision-maker to perceive a significant risk of not being able to self-insure or to pay the deductible when being formally insured. The predictions concerning the connection between income and insurance in particular warranty purchase hold as long as there is a sufficiently strong positive correlation between the size of the relevant budget and the household's overall income.

\subsection{Complementarity with previous behavioral approaches}

I want to underline how the adaptation I propose in this paper strongly complements with previous approaches assuming distorted probability weights and/or loss aversion. With such modifications the willingness-to-pay for a insurance is given by

$$
\tilde{w}=\omega(\pi \rho) \lambda V+\omega(\pi(1-\rho)) \lambda p
$$

where $\omega(\cdot)$ denotes a probability-weighting function and $\lambda>1$ is a parameter measuring the degree of loss aversion. ${ }^{22}$ It is easy to see that the impact of loss aversion is stronger in our case, as the customer does anticipate a loss greater than the cost $p$ with positive probability. Also, since the loss is greater than $p$, the impact of overweighting the loss probability is larger. This is further strengthened by the fact that the loss may take two different values. The probability-weighting function is typically assumed to be sub-additive, so $\omega(\pi \rho)+\omega(\pi(1-\rho))>\omega(\pi)$. Thus, the fact that the loss may take two different values depending on the realization of the budget risk, further strengthens the role of probability-distortions in explaining overinsurance.

\footnotetext{
${ }^{21}$ See e.g. Thaler (1990), Heath and Soll (1996), Thaler (1999), and Hastings and Shapiro (2012).

${ }^{22}$ I make the conventional assumption that the payment of the insurance premium is not regarded as a loss.
} 
I conclude that the adaptation we propose nicely complements with previous approaches to model consumer mistakes in insurance purchase. It adds explanations for empirical patterns that could not be accomodated before, while strengthening the impact of previously-identified consumer mistakes in that context.

\subsection{Relation to the Literature on Background Risk and Risk Aversion}

There is a large body of literature on how an independent background risk can change a person's inclination towards taking over a given risk. ${ }^{23}$ This literature shows that when preferences exhibit decreasing absolute risk aversion, then an independent, uninsurable background risk makes a person more willing to take up insurance against a risk that he can insure against. The evidence on decreasing absolute risk aversion reported by e.g. Guiso and Paiella (2008) indicate that this is relevant idea. In addition, given that the common example of an uninsurable background risk is a person's income risk, it is straightforward to think about a relation with the adaptation proposed here.

I want to point out that the results presented here are independent of this literature on background risk. First, the above literature points out how one insurance motive, i.e. consumptionsmoothing across states, changes due to background risk. Given that I consider an entirely different insurance motive, the access motive, the results on how background risk affects risk aversion do not apply here. This is all the more obvious as I consider the case of risk neutrality throughout the paper. In consequence, the results that are proposed here cannot be a consequence of the budget risk influencing the individual's risk preferences.

Second, the main focus of this paper is an attempt to better understand insurance behavior when stakes are modest, i.e. warranty purchase and deductible avoidance. Since people should be approximately risk neutral towards stakes of such size, the literature on the impact of background risk on risk aversion is less helpful for the questions I investigate.

All this being said, it does not mean that there is no interesting connection to this literature. In section 4, I show that a budget risk leads some loss states to be effectively excluded from coverage if benefits are paid conditionally or by reimbursement. This claim risk matters for a risk neutral individual. It matters all the more if someone is risk averse. Since the claim risk decreases

\footnotetext{
${ }^{23}$ See e.g. Pratt and Zeckhauser (1987), Kimball (1990), Kimball (1993), Gollier and Pratt (1996), and Eeckhoudt, Gollier, and Schlesinger (1996).
} 
in income, the value of insurance falls more dramatically for poorer consumers depending on whether benefits are paid unconditionally, conditionally, or by reimbursement. If lower income groups exhibit, in addition, a stronger degree of risk aversion this further reinforces the decline in value. This suggests an important complementarity between the results on budget risk presented here and the results on the impact of background (income) risk on risk aversion. It points to a very promising avenue for further research.

\section{Conclusion}

In this paper, a simple adaptation of the standard model of insurance is proposed that can help to account for various empirical observations that have been made in the context of warranty demand. Allowing consumers to perceive a risk of not being able to replace a broken product helps explain the observation of a positive correlation between product value and the value of a warranty. It strengthens the role of probability weighting and loss aversion in explaining firms' ability to reap significant profits from the sale of warranties. Finally, it helps to reconcile seemingly conflicting empirical evidence regarding the effect of household income on warranty demand.

The same adaptation is able to explain the context sensitivity of deductible avoidance. In addition, the resulting model predicts the value and cost of insurance to be strongly influenced by the the way benefits are paid. This can account both for the observation of deductible avoidance for flood insurance and the lack of similar evidence in the context of long-term care insurance.

Given the significant role of warranties as a source of profit in many branches and the significant role that deductibles play in insurance markets, it is important to reach a better understanding of consumer behavior with respect to these devices. Probability misperceptions and loss aversion have been identified as significant aspects of this behavior. I argue that a broader view on what constitute insurance motives may further our understanding as well.

The proposed adaptation suggests strong complementarities to both the standard approach and behavioral approaches to insurance. Risk aversion and differences in risk tastes have a stronger influence on insurance behavior if people perceive a claim risk. Probability weighting and loss aversion have a stronger impact if people perceive an access value. I conclude that this simple adapation offers a broad scope for further investigation. 


\section{References}

Barseghyan, L., F. Molinari, T. O'Donoghue, and J. C. Teitelbaum (2013). The nature of risk preferences: Evidence from insurance choices. American Economic Review 103(6), 24992529.

Barseghyan, L., J. Prince, and J. Teitelbaum (2011). Are risk preferences stable across contexts? evidence from insurance data. American Economic Review 101(2), 591-631.

Brown, J. R. and A. Finkelstein (2007). Why is the market for long-term care insurance so small? Journal of Public Economics 91, 1967-1991.

Businessweek (2004). The warranty windfall. http://www.bloomberg.com/bw/stories/2004-1219/the-warranty-windfall.

Chark, R. and A. Muthukrishnan (2013). The effect of physical possession on preference for product warranty. Interational Journal of Research in Marketing 30, 424-425.

Chen, T., A. Kalra, and B. Sun (2009). Why do consumers buy extended service contracts? Journal of Consumer Research 36, 611-623.

Chu, J. and P. K. Chintagunta (2011). An empirical test of warranty theories in the U.S. computer server and automobile markets. Journal of Marketing 75, 75-92.

Cutler, D. M. and R. Zeckhauser (2004). Extending the Theory to Meet the Practice of Insurance. Washington DC: Brookings Institution.

Eeckhoudt, L., C. Gollier, and H. Schlesinger (1996). Changes in background risk and risk taking behavior. Econometrica 64 (3), 683-689.

Gollier, C. and J. Pratt (1996). Risk vulnerability and the tempering effect of background risk. Econometrica 64(5), 1109-1123.

Guiso, L. and M. Paiella (2008). Risk aversion, wealth, and background risk. Journal of the European Economic Association 6(6), 1109-1150.

Hastings, J. and J. Shapiro (2012). Mental accounting and consumer choice: Evidence from commodity price shocks. NBER Working Paper Series (18248).

Heath, C. and J. B. Soll (1996). Mental budgeting and consumer decisions. Journal of Consumer Research 23(1), 40-52. 
Jindahl, P. (2014). Risk preferences and demand drivers of extended warranties. Marketing Science 34(1), 39-58.

Johnson, E., J. Hershey, J. Meszaros, and H. Kunreuther (2000). Framing, Probability Distortions, and Insurance Decisions. Cambridge University Press.

Kimball, M. S. (1990). Precautionary saving in the small and in the large. Econometrica 58(1), 53-73.

Kimball, M. S. (1993). Standard risk aversion. Econometrica 61(3), 589-611.

Michel, C. (2014). Contractual structures and consumer misperceptions - the case of product warranties. Working Paper.

Michel-Kerjan, E. and C. Kousky (2010). Come rain or shine: Evidence on flood insurance purchases in florida. The Journal of Risk and Insurance 77(2), 369-397.

Nyman, J. (2003). The Theory of Demand for Health Insurance. Stanford University Press.

OFT (2012). Extended warranties on domestic electrical goods: An OFT market study and notice of the OFT's intention to accept undertakings in lieu of a market investigation reference. http://webarchive.nationalarchives.gov.uk/20140402142426/http://oft.gov.uk/shared_oft/marketswork/OFT1403.pdf.

Padmanabhan, V. and R. C. Rao (1993). Warranty policy and extended service contracts: Theory and an application to automobiles. Marketing Science 12(3), 230-247.

Pratt, J. and R. Zeckhauser (1987). Proper risk aversion. Econometrica 55(1), 143-154.

Rabin, M. (2000). Risk aversion and expected-utility theory: A calibration theorem. Econometrica $68(5), 1281-1292$.

Rabin, M. and R. H. Thaler (2001). Anomalies: Risk aversion. The Journal of Economic Perspectives 15(1), 219-232.

Sydnor, J. (2010). (Over)insuring modest risks. American Economic Journal: Applied Economics 2, 177-199.

Thaler, R. H. (1990). Anomalies: Saving, fungibility, and mental accounts. Journal of Economic Perspectives 4(1), 193-205.

Thaler, R. H. (1999). Mental accounting matters. Journal of Behavioral Decision Making 12, $183-206$. 
Warranty Week (2014). Mid-year service contract report. http://www.warrantyweek.com/archive/ww20141009.html.

\section{Appendix}

\section{Proof of Proposition 1}

A risk-neutral individual derives a utility

$$
\mathbb{E} u_{0}=(1-\pi) V+\pi(1-\rho)(V-p)
$$

from self-insuring while deriving utility

$$
\mathbb{E} u_{I}=u(V-w)
$$

from buying insurance that fully pays $p$ in case of a loss. The maximal willingness-to-pay $\bar{w}$ is then given by

$$
\begin{aligned}
& \mathbb{E} u_{I}=V-\bar{w}=\mathbb{E} u_{0}=(1-\pi) V+\pi(1-\rho)(V-p) \\
\Leftrightarrow & \bar{w}=\pi(\rho V+(1-\rho) p) .
\end{aligned}
$$

\section{Proof of Proposition 2}

The maximal willingness-to-pay for an insurance specifying a deductible $r$ is given by

$$
\bar{w}(r)=\pi[(p-r)+\rho(V-p)-\delta(V-r)] .
$$

The maximal willingness-to-pay to replace a higher by a lower deductible is then given by

$$
\begin{aligned}
\bar{w}\left(r_{l}\right)-\bar{w}\left(r_{h}\right) & =\pi\left[r_{h}-r_{l}-F\left(r_{l}\right)\left(V-r_{l}\right)+F\left(r_{h}\right)\left(V-r_{h}\right)\right] \\
& =\pi\left[r_{h}-r_{l}+\left(F\left(r_{h}\right)-F\left(r_{l}\right)\right)\left(V-r_{l}\right)-F\left(r_{h}\right)\left(r_{h}-r_{l}\right)\right] .
\end{aligned}
$$


It follows that

$$
\bar{w}\left(r_{l}\right)-\bar{w}\left(r_{h}\right)>\pi\left(r_{h}-r_{l}\right) \Leftrightarrow \frac{F\left(r_{h}\right)-F\left(r_{l}\right)}{F\left(r_{h}\right)}>\frac{r_{h}-r_{l}}{V-r_{l}} .
$$

\section{Proof of Proposition 3}

Note that the difference between the willingness-to-pay of the high-risk and the low-risk group can be expressed as

$$
\bar{w}_{H}-\bar{w}_{L}=\phi(p)-\phi(r) .
$$

If $F_{\theta}(0)=0, \theta=H, L$, then $\phi(0)=\phi(V)=0$. Since $F_{H}(x)-F_{L}(x)>0$ for some $0<x<V$ by assumption, $\phi(x)$ must have an interior maximum $x^{*} \in(0, V)$. Since $F_{H}$ and $F_{L}$ are continuous, so is $\phi(x)$. Hence, there exist $p \in\left(x^{*}, V\right)$ such that $\phi(p)<\phi\left(x^{*}\right)$. And for any such $p$, there exists a value $r$, specifically $r=x^{*}$, such that $\phi(p)-\phi(r)<0$ and hence $\bar{w}_{H}(r)<\bar{w}_{L}$.

Suppose, in addition, that $\phi(x)=\left(F_{H}(x)-F_{L}(x)\right)(V-x)$ has a unique interior maximum $x^{*}$ with $\phi^{\prime}(x)>0, \forall x<x^{*}$ and $\phi^{\prime}(x)<0, \forall x>x^{*}$. Then for any $p<x^{*}, \phi(x)<\phi(p)$ for all $x<p$, and, hence, there exists no $0<r<p$ such that $\bar{w}_{H}(r)<\bar{w}_{L}$. On the other hand, if $p>x^{*}$ there exists a unique $r^{*}<x^{*}$ such that $\phi\left(r^{*}\right)=\phi(p)$. Since $\phi^{\prime}(x)>0, \forall x \in\left[r^{*}, x^{*}\right)$ and $\phi^{\prime}(x)<0, \forall x \in\left(x^{*}, p\right]$, we know that $\phi(x)>\phi(p), \forall x \in\left(r^{*}, p\right)$. Thus, for all $r \in\left(r^{*}, p\right)$, $\bar{w}_{H}<\bar{w}_{L}$. Since $\phi^{\prime}(x)>0, \forall x \in[0, r]$, we know that $\phi(x)<\phi\left(r^{*}\right), \forall x<r^{*}$. Hence, for all $r<r^{*}$, $\bar{w}_{H}>\bar{w}_{L}$.

Since $r^{*}$ is implicitly defined by $\phi(p)=\phi(r)$, and we know that $r^{*} \leq x^{*}$, and $\phi^{\prime}(x) \geq 0, \forall x \leq$ $x^{*}$, we know that $r^{*}$ declines in $\phi(p)$. With our assumptions on $\phi^{\prime}(x), \phi(x)=0$ only for $x=0$ and $x=V$. So, as $\phi(p)$ converges to zero, so must $\phi\left(r^{*}\right)$. Hence, $r^{*}$ converges to zero as well.

\section{Proof of Proposition 4}

Given our assumption on $\phi_{j}, j=H M, H L, M L$, we know from Proposition 3 that $r_{H M}^{*}, r_{H L}^{*}, r_{M L}^{*}$ are unique values. By definition, $\phi_{H L}\left(r_{H L}^{*}\right)=\phi_{H L}(p)$. By assumption, it then holds that $\phi_{M L}\left(r_{H L}^{*}\right) \leq \phi_{M L}(p)$. We can rule out that $x_{M L}^{*}<r_{M L}^{*}<p$, for that would imply $\phi_{M L}\left(r_{H L}^{*}\right)>$ $\phi_{M L}(p)$, since $\phi_{M L}^{\prime}(x)<0, \forall x \in\left(x_{M L}^{*}, p\right)$. Since $\phi^{\prime}(x) \geq 0, \forall x \leq x_{M L}^{*}$ and $\phi_{M L}\left(r_{H L}^{*}\right) \leq \phi_{M L}(p) \leq$ 
$\phi_{M L}\left(x_{M L}^{*}\right)$, we can conclude that there exists a unique $r \geq r_{H L}^{*}$ such that $\phi_{M L}(r)=\phi_{M L}(p)$. Yet, this unique $r$ is exactly $r_{M L}^{*}$. Hence, $r_{M L}^{*} \geq r_{H L}^{*}$.

Finally, note that $\phi_{H M}(x)=\phi_{H L}(x)-\phi_{M L}(x)$. Thus, since at $r_{H L}^{*}, \phi_{H L}(p)-\phi_{H L}\left(r_{H L}^{*}\right)=0$ and $\phi_{M L}(p)-\phi_{M L}\left(r_{H L}^{*}\right) \leq 0$, it follows that $\phi_{H M}(p)-\phi_{H M}\left(r_{H L}^{*}\right) \geq 0$. Since $\phi_{H M}(p)-\phi_{H M}(r) \leq 0$ for all $r \geq r_{H M}^{*}$, with strict inequality for all $r_{H M}^{*}<r<p$, we conclude that $r_{H M}^{*} \leq r_{H L}^{*}$.

\section{Proof of Proposition 5}

In all three cases the expected utility from self-insuring is given by

$$
\mathbb{E} u_{0}=(1-\pi) V+\pi(1-\rho)(V-p)
$$

The expected utility from insuring when benefits are paid unconditionally is given by

$$
\mathbb{E} u_{I(u c)}=(1-\pi)(V-w)+\pi[(1-\delta)(V-r-w)+\delta(p-r-w)]
$$

The expected utility from insuring when benefits are paid conditionally is given by

$$
\mathbb{E} u_{I(c)}=(1-\pi)(V-w)+\pi[(1-\delta)(V-r-w)+\delta(-w)]
$$

Finally, the expected utility from insuring when benefits are paid by reimbursement is given by

$$
\mathbb{E} u_{I(r i)}=(1-\pi)(V-w)+\pi[(1-\rho)(V-r-w)+\rho(-w)]
$$

The maximal willingness-to-pay for an insurance of a specific payment type can simply be derived by finding the level $w$ at which the individual is indifferent between self-insuring and buying formal insurance:

$$
\begin{aligned}
\mathbb{E} u_{I(u c)} & =\mathbb{E} u_{0} \Leftrightarrow \bar{w}_{u c}=\pi[(p-r)+(\rho-\delta)(V-p)], \\
\mathbb{E} u_{I(c)} & =\mathbb{E} u_{0} \Leftrightarrow \bar{w}_{c}=\pi[(p-r)+\rho(V-p)-\delta(V-r)], \\
\mathbb{E} u_{I(r i)} & =\mathbb{E} u_{0} \Leftrightarrow \bar{w}_{r i}=\pi[(1-\rho)(p-r)] .
\end{aligned}
$$


At the same time, an insurer needs to pay the benefit $(p-r)$ whenever a loss occurs under unconditional payment, when a loss occurs and the insuree is able to pay $r$ under conditional payment, and when a loss occurs and the insuree is able to pay $p$ under reimbursement. This straightforwardly gives the expected cost of coverage, i.e. the actuarially fair prices of insurance:

$$
\begin{aligned}
& f_{u c}=\pi(p-r), \\
& f_{c}=\pi(1-\delta)(p-r), \\
& f_{r i}=\pi(1-\rho)(p-r) .
\end{aligned}
$$




\section{Working Paper Series in Economics}

recent issues

No. 69 Markus Fels: Mental accounting, access motives, and overinsurance, May 2015

No. 68 Ingrid Ott and Susanne Soretz: Green attitude and economic growth, May 2015

No. 67 Nikolaus Schweizer and Nora Szech: Revenues and welfare in auctions with information release, April 2015

No. 66 Andranik Tangian: Decision making in politics and economics: 6. Empirically constructing the German political spectrum, April 2015

No. 65 Daniel Hoang and Martin Ruckes: The effects of disclosure policy on risk management incentives and market entry, November 2014

No. 64 Sebastian Gatzer, Daniel Hoang, Martin Ruckes: Internal capital markets and diversified firms: Theory and practice, November 2014

No. 63 Andrea Hammer: Innovation of knowledge intensive service firms in urban areas, October 2014

No. 62 Markus Höchstötter and Mher Safarian: Stochastic technical analysis for decision making on the financial market, October 2014

No. 61 Kay Mitusch, Gernot Liedtke, Laurent Guihery, David Bälz: The structure of freight flows in Europe and its implications for EU railway freight policy, September 2014

No. 60 Christian Feige, Karl-Martin Ehrhart, Jan Krämer: Voting on contributions to a threshold public goods game - an experimental investigation, August 2014

No. 59 Tim Deeken and Ingrid Ott: Integration as a spatial institution: Implications for agglomeration and growth, July 2014 